\title{
Neuroendocrine Breast Carcinoma: Case Report and Review of the Literature
}

\author{
Maha Abdel Hadi ${ }^{a} \quad$ Nosiaba Telmesani ${ }^{a} \quad$ Afnan Al Muhanna $^{b} \quad$ Ayesha Ahmed $^{c}$ \\ Haitham Kussaibic Muhammad Iftikhar ${ }^{\mathrm{a}}$ Mohammad Athar Nizami ${ }^{\mathrm{b}}$
}

Arwa A. Nabhand

aBreast Division, Department of Surgery, Imam Abdulrahman Bin Faisal University, Dammam, Saudi Arabia; ${ }^{b}$ Radiology Department, Imam Abdulrahman Bin Faisal University, Dammam, Saudi Arabia; 'Pathology Department, Imam Abdulrahman Bin Faisal University, Dammam, Saudi Arabia; dDepartment of Medicine, Oncology Unit, Imam Abdulrahman Bin Faisal University, Dammam, Saudi Arabia

\section{Keywords}

Breast cancer - Neuroendocrine carcinoma - Nuclear scan .

Oncology $\cdot$ Pathology $\cdot$ Radiology

\begin{abstract}
Primary breast carcinoma with neuroendocrine features is an uncommon presentation of mammary cancers. The authors present a case of a rapidly growing breast mass that raised many differential diagnoses. The diagnosis in this case was challenging. Extensive clinical assessment, radiological imaging, nuclear scans, pathological evaluations, and series of multidisciplinary meetings were utilized to reach the diagnosis of neuroendocrine breast carcinoma.

\author{
(c) 2021 The Author(s) \\ Published by S. Karger AG, Basel
}

The clinical and radiological features may not differ from other invasive cancers; however, the diagnosis is solely made on the discovery features similar to neuroendocrine tumors arising from the gastrointestinal tract or lungs. These tend to express neuroendocrine markers in $>50 \%$ of cases [4].

\section{Case Report}

A 40-year-old Asian female, a mother of 3 children (14 years, 7 years, and 10 months old), resident of the same area for the past 8 years, while lactating she noticed a rapidly growing left mass of 2-month duration. There were no associated pain, discharge, skin changes, or systemic manifestations. Gynecological history was unremarkable with regular menstrual cycles and intermittent use of oral contraceptive pills. There was no family history of breast cancer or similar a presentation.

\section{General Examination Was Unremarkable}

The reported incidence of the rare neuroendocrine breast tumors comprises $2-5 \%$ of all breast carcinomas. The diagnosis depends mainly on the radiologically and histopathologically detected criteria $[1,2]$. The World Health Organization categorized these tumors as a subtype of invasive breast cancer based on endocrine features [3]. karger@karger.com www.karger.com/dmj

Karger $\stackrel{\text { ' }}{=}$
(C) 2021 The Author(s)

Published by S. Karger AG, Basel

This article is licensed under the Creative Commons AttributionNonCommercial-NoDerivatives 4.0 International License (CC BY NC-ND) (http://www.karger.com/Services/OpenAccessLicense) Usage and distribution for commercial purposes as well as any distribution of modified material requires written permission.
Local examination revealed breast asymmetry, with a 4 -fold increase in the left breast size. A $10 \times 12-\mathrm{cm}$ mass occupied both lower and lateral quadrants extending from 2 and 7 o'clock. The overlying skin was stretched and edematous, with areas of peau d'orange. Nipple and 
the areola complex were stretched but uncompromised. A large $3 \times 3-\mathrm{cm}$ solitary, mobile nontender lymph node was palpated in the ipsilateral axilla (Fig. 1).

The primary clinical impression was locally advanced breast cancer. Initial standard investigations included ultrasound (Fig. 2) and mammogram (Fig. 3a, b), followed by FNAC and core needle biopsy. Cytology was reported as positive for malignant cells. Core biopsy showed an undifferentiated malignant neoplasm with markedly atypical, hyperchromatic, pleomorphic cells with abundant mitosis and apoptosis. Scattered foci of necrosis were also evident (Fig. 4a, b).

Computed tomography and nuclear bone scans both demonstrated the breast lesion with no evidence of distal metastasis (Fig. 5). Technetium-99m-octreotide scan confirmed isotope uptake in both the left breast mass and the ipsilateral axillary node consistent with positive somatostatin receptor lesions (Fig. 6a, b).
Fig. 1. Clinical appearance at presentation with obvious asymmetry and overstretched overlying skin and edema of the left breast.

Fig. 2. Ultrasound: large lobulated heterogeneous hypoechoic mass occupying the left lateral breast; gray scale and shear wave elastography demonstrated the mass with peripheral blue ring on elastography, highly suspicious of malignancy.

Fig. 3. a, b Mammography of the left breast: $\mathrm{CC}$ and MLO views demonstrate a partially circumscribed hyperdense mass with overlying skin thickening, highly suspicious for malignancy, BI-RADS 4C.
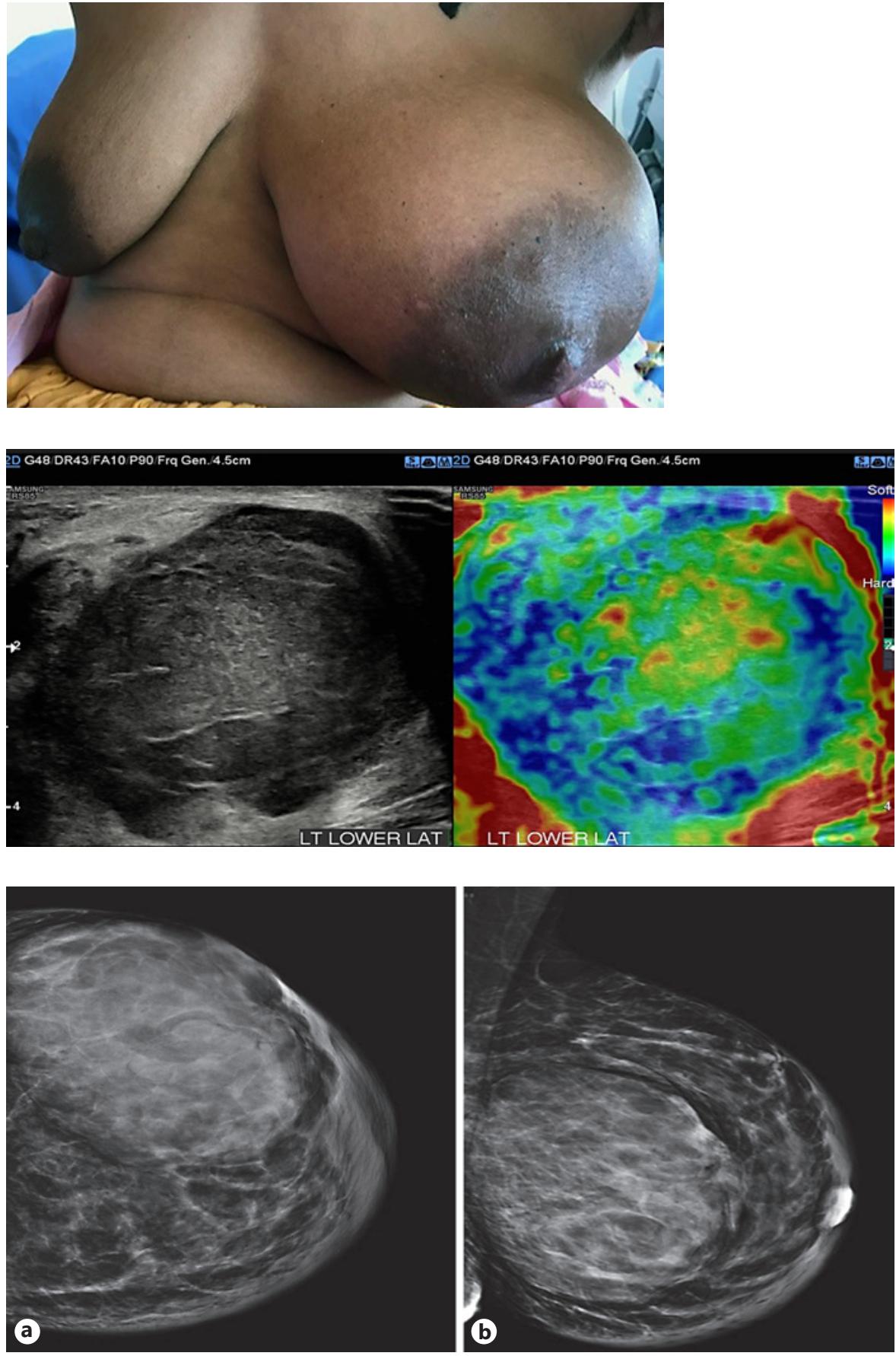
Fig. 4. a, b $5 \times$ and $10 \times$ microscopic picture demonstrating tumor invading the nearby breast parenchyma as obtained from the core biopsy.
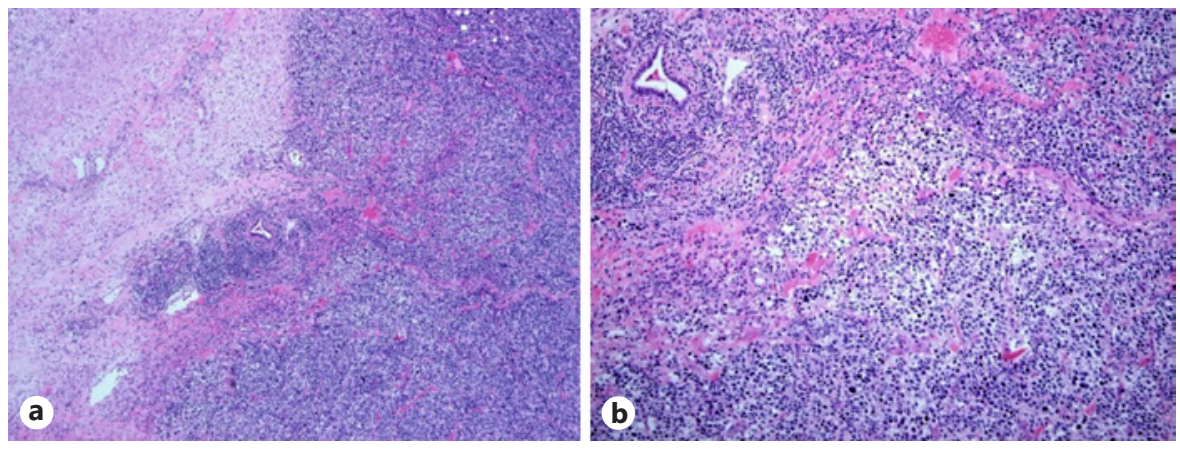

Fig. 5. Tc-99m HDP bone scan. Anterior and posterior views. Heterogeneous soft tissue tracer uptake noted within the left breast correlating to the extensive primary left breast mass. There is no scintigraphic evidence of any obvious sinister osseous lesions in this study.

Mastectomy with axillary dissection was the consensus based on the lengthy discussion of the multidisciplinary meeting. Intraoperatively, the large firm mass was found to be firmly attached to the overlying stretched, edematous skin with no adherence to deep fascia (Fig. 7a, b).

The mastectomy specimen weighed $700 \mathrm{~g}$, measuring $19 \times 9 \times 13 \mathrm{~cm}$. The mass appeared well circumscribed and gray to white in color with areas of hemorrhage and necrosis. A number of matted axillary lymph nodes were recovered and the largest measured $4.4 \times 2 \mathrm{~cm}$ (Fig. $7 \mathrm{c}$, d).

Microscopic examination of the mass revealed malignant cells arranged in diffuse pattern with focal rosette formation and prominent vascularity. The cells showed cellular and nuclear pleomorphism, finely granular, salt and pepper chromatin, scattered apoptosis, and extensive necrosis (Fig. 8).

A large panel of immunohistochemical analysis was performed which included Pan-CK, CK5/6, CK-7, CK8/18, HMW-CK, E-cadherin, Mammaglobin, GCDFP-63, ER, PR, Her2/neu, vimentin, myeloperoxidase, CD-34, LCA.CD-68, PLAP, HMB-45, and chromogranin.
They were all reported as negative. Ki67 was reported of $95 \%$. And, immunocytochemical analysis of S100, CD56, and synaptophysin were reported as positive (Fig. 9).

Based on the cumulative data obtained from the clinical features, radiological images, nuclear uptake, morphological appearance, and the immunocytochemical markers, the final diagnosis of "poorly differentiated invasive neuroendocrine carcinoma" was reached. The patient had an uneventful postoperative course and was discharged in a good condition to be followed in an outpatient multidisciplinary clinic. At 6 months, the patient remains in good condition with no evidence of local recurrence.

\section{Discussion}

Thorough clinical evaluation, extensive radiological imaging coupled by nuclear scans and comprehensive pathological immunocytochemical analysis maybe required to reach the uncommon diagnosis of primary neuroendocrine breast carcinoma. The value of multidisci- 
6

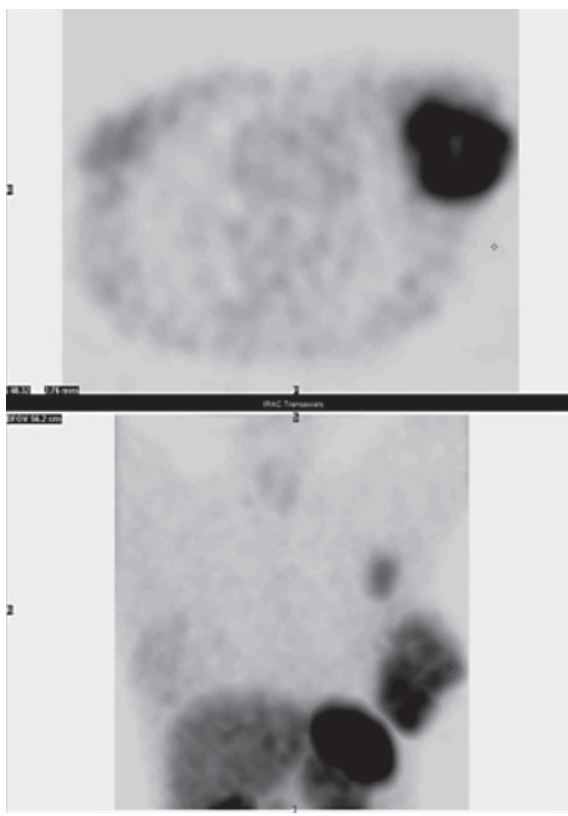

Fig. 6. Octreotide scan SPECT-CT: avid uptake at left breast mass and ipsilateral axillary lymph node with no other octreotide avid-detected lesions.

Fig. 7. The skin marking prior to the mastectomy (a), preserving as much as possible of normal skin (b), the firm specimen (c), and matted axillary nodes $(\mathbf{d})$.
7
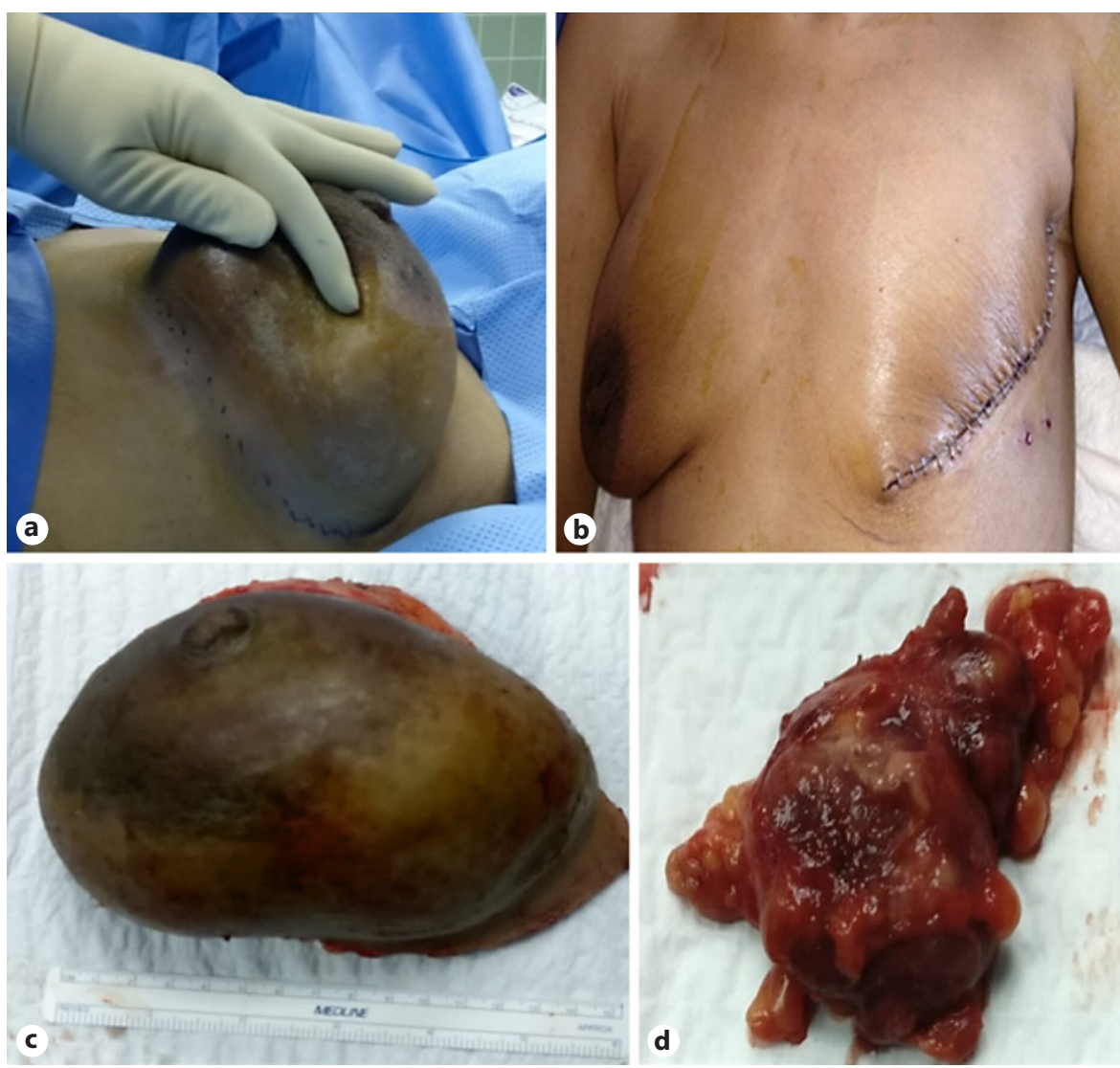

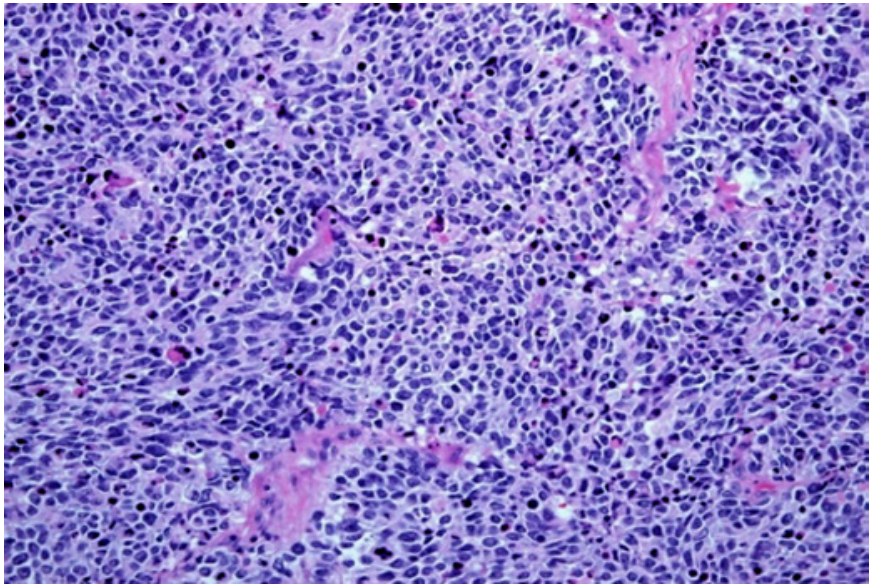

Fig. 8. 20× microscopic picture showing the tumor with prominent vascularity, many mitosis, and cell apoptosis.

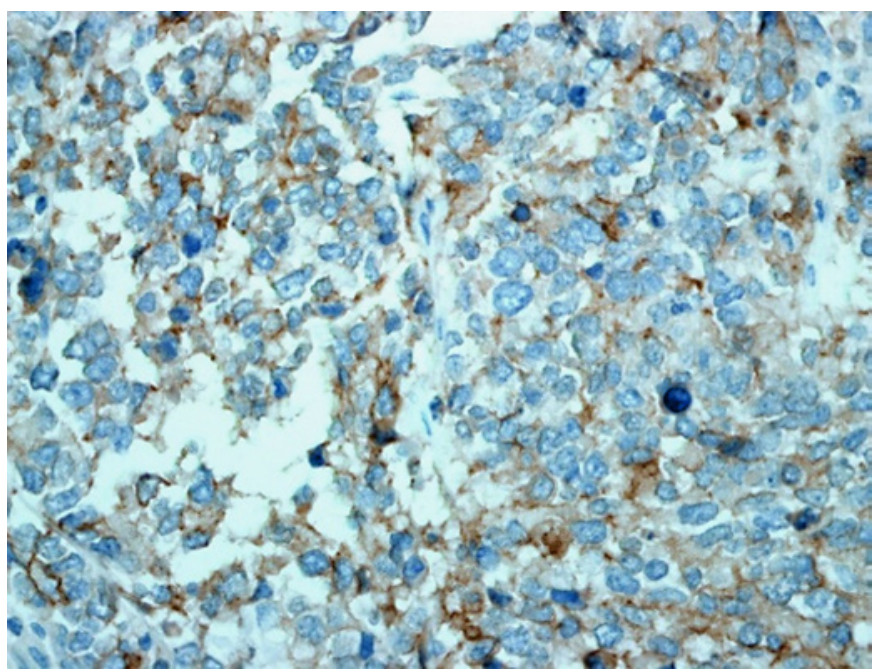

Fig. 9. 20× microscopy showing tumor cells positive for CD56. 
plinary team collaboration is of fundamental importance in the management of such cases [3].

Secondaries to the breast should be both radiologically and pathologically excluded prior to committing to the diagnosis of primary mammary carcinoma. Neuroendocrine tumors of the breast occur predominately in postmenopausal women; however, it has also been reported in younger patients.

Neuroendocrine tumors commonly originate from the gastrointestinal tract, pancreas, and lungs. The subclassification ranges from well-differentiated to poorly differentiated tumors.

Poorly differentiated neuroendocrine tumors morphologically resemble small cell carcinoma of the lung. Some invasive breast cancer may acquire neuroendocrine morphology features with positive markers [5].

Thirty percent of invasive breast carcinomas can express neuroendocrine differentiation specifically in mucinous and solid papillary carcinomas. The expression of the neuroendocrine markers synaptophysin or chromogranin is essential to confirm the diagnosis [6]. Many theories have suggested that neuroendocrine tumors arise from deviating differentiation of malignant cells with no preexisting neuroendocrine stem cells [7-9]. It is interesting to note that benign neuroendocrine tumors are not known to occur in the breast $[10,11]$.

Primary neuroendocrine carcinoma of the breast depicts distinct mammographic features that may differ from those of invasive mammary carcinoma. It may appear round, oval, well circumscribed, or lobulated masses that are usually categorized radiologically as BIRAD 4 [12].

PET/CT, CT scan, MRI, and endoscopy maybe helpful tools in aiding diagnosis [13]. The use of somatostatin receptor imaging maybe be of importance in accuracy of follow-up. Its reported sensitivity, specificity, accuracy, positive predictive value, and negative predictive value of Tc-99m-OCT scan were $96,100,97,100$, and $94 \%$, respectively [14].

Despite the reported poor outcomes, the standard management plan is no different from invasive breast cancer. Similar guidelines apply to the surgical options being breast-conserving surgery or mastectomy [15-17]. Adjuvant treatment regimens are generally based on immunohistochemistry.

Endocrine therapies may have an advantage in susceptible tumors. Somatostatin analogs are suggested for tumors with somatostatin receptor expression $[18,19]$. The diagnosis of primary poorly differentiated invasive neuroendocrine carcinoma is an uncommon challenging entity that requires diligent multimodality management.

\section{Statement of Ethics}

The authors hereby state that the patient has given her signed written informed consent through her guardian (husband), granting permission for all the materials used in the diagnosis and management to be published in a medical journal.

\section{Conflict of Interest Statement}

The authors have no conflicts of interest to declare.

\section{Funding Sources}

This study was self-financed.

\section{Author Contributions}

All authors contributed actively to this manuscript. The following list delineates the contribution of each author: (1) Maha Abdel Hadi (first author): case selection and designed and reviewed the manuscript, (2) Nosieba Telmisani: provision of the clinical account and literature review, (3) Afnan Al Muhanna: provision of images and radiological diagnosis, (4) Ayesha Ahmed: provision of histopathology slides and interpretation, (5) Haitham Kussaibi: provision of histopathology slides and interpretation, (6) Mohammed Iftikhar: provision of clinical account and literature review, (7) Mohmmad Nizami: provision of nuclear images and diagnosis, and (8) Arwa Nabhan: participation in clinical diagnosis and management plan.

References

1 Miremadi A, Pinder SE, Lee AH, Bell JA, Paish EC, Wencyk P, et al. Neuroendocrine differentiation and prognosis in breast adenocarcinoma. Histopathology. 2002;40(3):21522.

2 Makretsov N, Gilks CB, Coldman AJ, Hayes $\mathrm{M}$, Huntsman D. Tissue microarray analysis of neuroendocrine differentiation and its prognostic significance in breast cancer. Hum Pathol. 2003;34(10):1001-8.

3 Ellis IO, Schnitt SJ, Sastre-Garau X, Bussolati G. Invasive breast carcinoma. In: Tavassoli FA, Devilee P, editors. World Health Organization classification of tumours. Pathology and genetics of tumours of the breast and female genital organs. Lyon: IARC Press; 2003. p. 32-4.

4 Righi L, Sapino A, Marchiò C, Papotti M, Bussolati G. Neuroendocrine differentiation in breast cancer: established facts and unresolved problems. Semin Diagn Pathol. 2010; 27(1):69-76.

5 Oronsky B, Ma PC, Morgensztern D, Carter CA. Nothing but NET: a review of neuroendocrine tumors and carcinomas. Neoplasia. 2017;19(12):991-1002.
Abdel Hadi et al. 
6 Lauren ER, Paolo G. Neuroendocrine tumors of the breast. Arch Pathol Lab Med. 2017 Nov; 141(11):1577-81.

7 Hoang MP, Maitra A, Gazdar AF, AlboresSaavedra J. Primary mammary small-cell carcinoma: a molecular analysis of 2 cases. Hum Pathol. 2001;32(7):753-7.

8 Papotti M, Macrì L, Finzi G, Capella C, Eusebi V, Bussolati G. Neuroendocrine differentiation in carcinomas of the breast: a study of 51 cases. Semin Diagn Pathol. 1989;6(2):17488.

9 Miremadi A, Pinder SE, Lee AH, Bell JA, Paish EC, Wencyk P, et al. Neuroendocrine differentiation and prognosis in breast adenocarcinoma. Histopathology. 2002;40(3):21522.

10 Righi L, Sapino A, Marchiò C, Papotti M, Bussolati G. Neuroendocrine differentiation in breast cancer: established facts and unresolved problems. Semin Diagn Pathol. 2010; 27(1):69-76.
11 Maluf HM, Koerner FC. Carcinomas of the breast with endocrine differentiation: a review. Virchows Arch. 1994;425(5):449-57.

12 Park YM, Wu Y, Wei W, Yang WT. Primary neuroendocrine carcinoma of the breast: clinical, imaging, and histologic features. AJR Am J Roentgenol. 2014;203(2):W221-30.

13 Guo W, Hao B, Luo N, Ruan D, Guo X, Chen $\mathrm{HJ}$, et al. Early re-staging and molecular subtype shift surveillance of locally recurrent or metastatic breast cancer: a new PET/CT integrated precise algorithm. Cancer Lett. 2018; 418:221-9.

14 Al Bulushi N, Al Saqri B, Al Amri M, Al Hadidi A, Al Jahdami H, Al Zadjali M, et al. Diagnostic accuracy of technetium-99m-octreotide in imaging neuroendocrine, our experience with literature review. Clin Oncol. 2017; $2: 1361$.
15 Shin SJ, DeLellis RA, Ying L, Rosen PP. Small cell carcinoma of the breast: a clinicopathologic and immunohistochemical study of nine patients. Am J Surg Pathol. 2000;24(9):12318.

16 Chua RS, Torno RB, Vuletin JC. Fine needle aspiration cytology of small cell neuroendocrine carcinoma of the breast. A case report. Acta Cytol. 1997;41(4 Suppl 1):1341-4.

17 Sebenik M, Nair SG, Hamati HF. Primary small cell anaplastic carcinoma of the breast diagnosed by fine needle aspiration cytology: a case report. Acta Cytol. 1998;42(5):1199203

18 Watrowski R, Jäger C, Mattern D, Horst C. Neuroendocrine carcinoma of the breast: diagnostic and clinical implications. Anticancer Res. 2012;32(11):5079-82. .

19 Saeed A, Rehman A, Zaidi SA, Shaukat T, Jamil K, Abdullah K. Neuroendocrine carcinoma of breast. J Coll Physicians Surg Pak. 2011;21(6):371-3. 